\title{
Análise ergonômica da atividade dos músicos da Orquestra Sinfônica do Paraná: fatores de risco e cargas de trabalho ${ }^{1}$
}

\author{
Jaqueline de Lima ${ }^{a}$, Angela Paula Simonellia \\ ${ }^{a}$ Curso de Terapia Ocupacional, Universidade Federal do Paraná - UFPR, Curitiba, PR, Brasil
}

\begin{abstract}
Resumo: O presente estudo objetivou investigar os fatores de risco presentes na atividade de trabalho e seu impacto na saúde dos músicos instrumentistas da Orquestra Sinfônica do Paraná. Enquadra-se como uma pesquisa qualitativa descritiva, a partir do método da Análise Ergonômica do Trabalho francofônica, utilizado enquanto ferramenta do terapeuta ocupacional na interface saúde-trabalho. Foram realizados os procedimentos: levantamento bibliográfico; análise documental dos dados de produtividade, produção e qualidade da tarefa; observação sistemática dos ensaios da Orquestra Sinfônica do Paraná; análise da tarefa e do posto de trabalho, com a aplicação do Ergonomic Workplace Analysis (EWA); e confrontação dos dados analisados com um músico instrumentista. Como resultados, o estudo apontou desvios significativos dos padrões descritos na Norma Regulamentadora 17 (Ergonomia), especialmente quanto às exigências físicas e cognitivas individuais, bem como quanto às relacionadas à organização do trabalho, considerando cada item avaliado pelo instrumento. Fundamentou-se a ação do terapeuta ocupacional pela inserção no processo saúde e adoecimento, na promoção da saúde, prevenção do adoecimento e formação dos músicos enquanto trabalhadores e atores sociais, vislumbrando a transformação das situações de trabalho.
\end{abstract}

Palavras-chave: Música, Ergonomia, Terapia Ocupacional, Saúde do Trabalhador.

\section{Ergonomic activity analysis of the musicians of the Symphony Orchestra of Paraná state: risk factors and workloads}

\begin{abstract}
This study aimed to investigate the risk factors present in the work activity and their impact on the health of the musicians of the Symphony Orchestra of Parana state. It is a descriptive qualitative research based on the method of Ergonomic Workplace Analysis of Francophone strand, used as a tool by occupational therapists in the health-work interface. The following procedures were performed: bibliographical survey, documental analysis of productivity data, production and quality of the task, systematic observation of the rehearsals of the Symphony Orchestra of Parana, task and workplace analysis with the application of Ergonomic Workplace Analysis (EWA) and, confrontation of the data analyzed with an instrumental musician. As a result, the study showed significant deviations with reference to the standards described in Brazilian Norm 17 (Ergonomics), especially regarding individual cognitive and physical demands as well as demands related to work organization, considering each item evaluated by this analytical instrument. The action of occupational therapy was grounded on the insertion in the health and illness process, health promotion, illness prevention, and training of musicians as workers and social actors, envisioning the transformation of work situations.
\end{abstract}

Keywords: Music, Ergonomics, Occupational Therapy, Occupational Health. 


\section{Introdução}

O fazer musical correspondente à atividade do músico pode ser analisado enquanto continuum por ser necessária a manutenção das habilidades e aperfeiçoamento das competências para atingir grau crescente de expertise. Representa um processo de ensino-aprendizagem que envolve funções motoras, cognitivas e psíquicas de alto nível (COSTA, 2003). Nos casos em que o exercício da música é também profissão, a demanda de esforço torna-se ainda maior, apesar de pressupor-se entre o ser humano e o instrumento uma combinação perfeita e gratificante (FRANK; VON MÜHLEN, 2007).

Constituída por aproximadamente 90 músicos, a instituição orquestra sinfônica é formada por naipes, grupos específicos de instrumentos musicais - cordas, sopros e percussão. A divisão do trabalho responde a uma estrutura hierárquica em cargos diferenciados como maestro, que é responsável pela elaboração do cronograma de trabalho e desenvolvimento das atividades propostas. $\mathrm{O}$ spalla ou primeiro violinista é o músico responsável pelo naipe que presta auxílio ao maestro na elaboração da programação e conduz os trabalhos de afinação da orquestra. Por vezes há a presença dos chefes de naipe que, juntamente com os primeiros, são responsáveis pelo posicionamento, coordenação da disciplina e assiduidade do seu naipe. Aos demais músicos da orquestra, ou "músicos de fila", cabe seguir as orientaçóes dos superiores no tocante à execução musical (PETRUS; ECHTERNACHT, 2004).

Quanto ao aporte físico necessário à atividade, segundo Moura, Fontes e Fukujima (2000, p. 104), o exercício muscular dos músicos é equiparado ao de um esportista, entretanto o conhecimento do envolvimento do corpo é significativamente mais limitado. As funçôes mentais, por outro lado, são evidenciadas principalmente em decorrência da interpretação frente ao público e resignação a possíveis críticas e cobranças hierárquicas, além da autocrítica (TRELHA et al., 2004). As condiçôes ambientais do local de trabalho - onde ocorrem os ensaios e concertos, comumente diversificados - são outros elementos geradores de exigência do trabalho (COSTA, 2003).

Nesse contexto, o conceito de carga de trabalho complementa a discussão do impacto dos processos de trabalho sobre a saúde dos sujeitos, correspondendo ao esforço necessário do trabalhador no cumprimento da tarefa imposta e/ou exigida (SELIGMANN-SILVA, 1994). Em correlação, Costa e Abrahão (2004) classificam três dimensôes no fazer musical - física, cognitiva e psíquica - que frequentemente se sobrepóem às habilidades que envolvem o fazer musical.

$\mathrm{Na}$ profissão musical a presença de dor tem sido objeto de pesquisas ao redor do mundo, pois seu mecanismo não é óbvio nem para os próprios músicos. Um fator que contribui para a negligência dos sintomas é a crença predominante de que a dor faz parte do tocar, incentivando práticas intensivas e desgastantes na busca constante pela perfeição. Dessa forma, os músicos tendem a procurar auxílio médico somente quando o sintoma já está instalado em seu cotidiano e interfere significativamente no desempenho profissional (COSTA, 2003).

A ocorrência de disfunçóes em músicos profissionais, apesar de ser observada há mais de um século, foi aprofundada a partir de 1980, quando projetos de pesquisa e intervenção pioneiros se iniciaram, especialmente no Canadá e nos Estados Unidos (CHONG et al., 1989; GONIK, 1991; OSTWALD et al., 1994; ZAZA, 1998).

A primeira pesquisa piloto, realizada em 1986, nos Estados Unidos, referiu que os diagnósticos mais comuns incluíam síndrome do superuso, tenossinovite, tendinite, compressôes nervosas, síndrome do túnel do carpo e doença do disco cervical (CHONG et al., 1989). No mesmo ano, a chamada "medicina do músico" teve sua consolidação com a publicação da revista Medical Problems of Performing Artists, publicada pela Performing Arts Medicine Association (PAMA), e na realização de investigação epidemiológica junto à International Conference of Symphony and Opera Musicians, com uma amostra de 2.212 respondentes, em que $82 \%$ reportaram adoecimento ao longo de sua carreira, sendo, pelo menos, uma disfunção grave em $76 \%$ dos músicos (CHONG et al., 1989; COSTA, 2003; GONIK, 1991). Já no final da década de 1980 foram encontrados ao menos 17 centros médicos especializados no tratamento do adoecimento de músicos, estimando-se que "[...] cerca de três quartos dos músicos de orquestra americanos sofrem de algum problema suficientemente grave para prejudicar sua performance." (GONIK, 1991, p. 9). Ressalta-se ainda a forte tendência de os índices mascararem a realidade do quadro, considerando que não incluem os casos de abandono da atividade (GONIK, 1991).

No Canadá, enquanto a profissão de músico frequentemente não inclui vínculo empregatício formal, apesar de corresponder a uma parcela significativa de contribuição à economia do país, são citados programas clínicos de prevenção e de reabilitação com equipe multidisciplinar especializada. Dentre as etapas do processo são descritas: avaliação do desempenho, coleta de informaçōes, 
acompanhamento das atividades musicais, sessóes grupais de alongamento, mobilização e recuperação, acompanhamento nutricional, discussão ergonômica e reavaliação final (CHONG et al., 1989).

$\mathrm{Na}$ Alemanha, um estudo realizado pelo médico e pianista brasileiro Marco Antônio de Almeida demonstrou que $75 \%$ dos instrumentistas de orquestras desse país relatam possuir algum tipo de problema de origem postural ou lesão por esforço repetitivo (LER) (ANDRADE; FONSECA, 2000).

No cenário nacional, Andrade e Fonseca (2000), num estudo realizado com instrumentistas de corda de instituiçốes de ensino de música, em amostra de 419 respondentes de 13 estados brasileiros apontou que $88 \%$ apresentavam desconforto físico, sendo $64,8 \%$ ligados à dor e que 30\% foram obrigados a interromper a atividade em razão dos sintomas. Destaca-se ainda o estudo com violinistas realizado por Costa e Abrahão (2004) utilizando a metodologia da Análise Ergonômica do Trabalho (AET) proposta por Guérin et al. (2001 apud COSTA; ABRAHÃO, 2004), que concluiu que "[...] a dor permanece em suas histórias de vida, necessitando ser gerenciada para dar continuidade ao exercício profissional." (COSTA; ABRAHÃO, 2004, p. 74).

Aliada à crescente preocupação acerca do impacto da profissão na saúde dos músicos, a inserção do terapeuta ocupacional em equipes multiprofissionais atuantes no contexto de trabalho considera sua capacitação no desenvolvimento de programas de prevençáo do adoecimento e reabilitação profissional a partir de ferramentas que permitem a relação entre as capacidades do indivíduo e as exigências da organização para o posto de trabalho determinado (WATANABE; NICOLAU, 2001). Enquanto método, a AET visa o conhecimento das habilidades requeridas para o desempenho da atividade de trabalho e das relaçóes que se estabelecem entre o ambiente humano e tecnológico, na busca de estratégias para a prevenção de riscos à saúde, promoção da segurança e bem-estar no trabalho (GUÉRIN et al., 2001).

Considerando a caracterização da atividade musical, bem como as dimensões envolvidas nesse fazer, o estudo que se segue foi realizado no contexto da Orquestra Sinfônica do Paraná (OSP), aproximando-se de suas configuraçôes e peculiaridades, objetivando a identificação e investigação de fatores de risco de ordem ergonômica na situação de trabalho e seu impacto sobre a categoria profissional dos músicos.

\section{Materiais e métodos}

A investigação das dimensōes do trabalho proposta nesse estudo foi apoiada nos princípios metodológicos da AET de vertente francofônica (GUÉRIN et al., 2001), buscando a compreensão da dinâmica da organização do trabalho e das condições nas quais ocorre a atividade. Baseando-se nos critérios de segurança, eficiência e bem-estar dos trabalhadores, bem como na articulação equilibrada entre eles, o método propóe açóes e raciocínios processuais visando a resolução de um "problema", conhecido por demanda, considerando a variabilidade dos indivíduos e da produção (WATANABE; GONÇALVES, 2004). Em consonância à AET proposta em Guérin et al. (2001), o Ergonomic Workplace Analysis (EWA) é um instrumento de origem finlandesa utilizado na busca de um consenso na análise detalhada de uma situação de trabalho, tarefa e/ou posto de trabalho, baseando-se nos preceitos da fisiologia do trabalho, biomecânica e higiene ocupacional em um modelo sociotécnico de organização. É composto por 14 itens: área de trabalho horizontal, atividade física geral, levantamento de cargas, posturas de trabalho e movimentos, riscos de acidente, conteúdo do trabalho, restriçốes no trabalho, comunicação entre trabalhadores e contatos pessoais, tomadas de decisão, repetitividade do trabalho, atenção, iluminação, ambiente térmico e ruído (AHONEM; LAUNIS; KUORINKA, 2001).

Segundo o EWA, a análise é realizada em três etapas: (1) delimitação da tarefa a ser analisada, ou subtarefas a serem analisadas separadamente; (2) descrição da tarefa, em lista de operaçóes e desenho do croqui, esboço do posto de trabalho; e (3) análise ergonômica, através da observação da situação real de execução da atividade. Nessa, os itens são classificados de forma qualiquantitativa em escala de um 1 a 5 , em que 1 representa uma situação de mínimo desvio em relação a uma condição adequada e os valores 4 e 5, a indicação de condiçôes potencialmente nocivas à saúde dos trabalhadores (AHONEM; LAUNIS; KUORINKA, 2001).

Após a realização da análise ergonômica observacional, o analista entrevista um trabalhador - que, no caso do trabalho ser executado por um grupo, atua como seu representante - e obtém seu julgamento acerca de cada item, a ser classificado por ele como bom (++), regular (+), ruim (-) ou muito ruim (--). A considerável discrepância entre a classificação do analista e o julgamento do trabalhador significa que a situação de trabalho deve ser investigada mais detalhadamente para a definição de um consenso (AHONEM; LAUNIS; 
KUORINKA, 2001). O universo da pesquisa correspondeu aos músicos instrumentistas que compóem a Orquestra Sinfônica do Paraná (OSP), com sede no Centro Cultural Teatro Guaíra, na cidade de Curitiba, Paraná. Náo foi delimitado, inicialmente, uma categoria instrumental ou subgrupo do total, sendo o trabalho realizado através da participação voluntária individual dos músicos - após a apresentaçáo do projeto e suas atribuiçóes ao grupo - e após concordância registrada em Termo de Consentimento Livre e Esclarecido dos participantes.

Os procedimentos da pesquisa foram executados em cinco etapas principais: (1) revisão de literatura sobre fatores de risco em situaçóes similares; (2) levantamento dos dados de produçáo, produtividade e qualidade, por meio de análise documental da agenda de ensaios e apresentaçóes da OSP; (3) aplicaçáo do instrumento Ergonomics Workplace Analysis (EWA), contando com a observaçáo sistemática dos ensaios e entrevista com um músico para confrontação das informaçôes colhidas; (4) caracterização dos fatores de risco presentes na tarefa e reconhecimento da compreensão do músico sobre os itens analisados e, finalmente; (5) definição de situaçôes críticas encontradas e discussão sobre hipóteses explicativas para a carga de trabalho.

Ressalta-se ainda que a terceira etapa foi realizada durante a observação de quatro dias aleatórios de ensaio da OSP, conforme a disponibilização da agenda pela direção da orquestra, totalizando 12 horas de observação. Foram incluídos registros das tarefas dos instrumentistas de cordas e sopro, citando peculiaridades de cada categoria.

\section{Resultados e discussão}

\subsection{Aplicação do EWA}

$\mathrm{Na}$ rotina de ensaios da OSP observou-se a tarefa de trabalho mais característica e frequente: a execução do instrumento musical (tocar), coletivamente. A OSP é composta de 76 músicos instrumentistas, que integram 22 categorias de instrumentos: 44 do naipe de cordas; 27 do naipe de sopros; três do naipe de percussão; e dois do naipe de cordas de tecla e dedilhadas.

O naipe de cordas e o naipe de sopros, respectivamente, permaneceram tocando os instrumentos por mais tempo durante os ensaios, o que corroborou dados da literatura acerca do significativo aumento na carga de trabalho físico e cognitiva desses músicos, quando comparada à dos demais.

Com a aplicação do EWA, após a análise ergonômica e a confrontação, foram identificados seis, dentre os 14 itens, que denunciaram situaçóesproblema na tarefa dos músicos: área de trabalho; atividade física geral; risco de adoecimento ocupacional; conteúdo do trabalho; tomada de decisão; e ambiente térmico.

\subsection{A carga de trabalho no contexto da OSP}

A área de trabalho foi considerada inadequada em relação aos padrões recomendados com referência ao ajuste antropométrico e à biomecânica ocupacional. O principal desvio foi evidenciado no tipo de assento, igual para todos os músicos, com encosto fixo e na não disponibilização de apoio lombar, para braços ou para pés, não possibilitando o conforto postural em atividades de período prolongado. Segundo Fragelli (2008), tais fatores tendem a dificultar a manutenção de uma postura adequada, o que gera desgastes físicos. Observou-se ainda que os itens apresentam-se inadequados com relação à Norma Regulamentadora 17 , que define parâmetros para adaptação das condições de trabalho visando o conforto, segurança e desempenho eficientes dos trabalhadores (BRASIL, 1990), conforme critérios dispostos no item 17.3 quanto ao mobiliário dos postos de trabalho em posição sentada. A adoção de posturas e movimentos tensos durante a jornada foi evidenciada durante a observaçáo dos ensaios coletivos enquanto mecanismo de regulaçáo individual.

A atividade física exercida pelos músicos da OSP apresentou-se diretamente proporcional aos picos de carga de trabalho, de frequência semanal, relacionados à proximidade da apresentação pública. O período de "pausa" no ensaio é determinado hierarquicamente, correspondendo a 20 minutos na metade do período de 3 horas do ensaio. A NR17 refere a necessidade da realização de pausas para descanso ao longo da jornada de trabalho em atividades que exijam sobrecarga muscular do pescoço, ombros, dorso e/ou membros superiores e membros inferiores (BRASIL, 1990), como é o caso do tocar em orquestra. Apesar de não ser comprovada infração à norma, evidenciou-se a necessidade de investigação mais aprofundada da atividade para determinar padróes adequados de pausa como fator de proteção à saúde dos músicos (CHONG et al., 1989; OSTWALD et al., 1994; ANDRADE; FONSECA, 2000). 
A tarefa de leitura dos músicos da OSP é executada com base em informaçôes insuficientemente claras, dentre as quais o fornecimento de partituras em fotocópia de qualidade questionável. Segundo Costa (2003), as condiçóes de iluminação, cor e tipo do papel da partitura, tamanho e espaçamento da fonte, bem como a qualidade da impressão podem ser associados à fadiga visual e adoção de posturas compensatórias. $\mathrm{O}$ item pode ser comparado ainda ao inciso 17.4.2 da NR17, que dispóe sobre equipamentos em condiçóes adequadas para a leitura de documentos, para digitação, datilografia ou mecanografia: a codificação da partitura e a demanda de coordenaçáao visual-motora para a execuçáo da obra contida no documento também consideram, para a sua efetividade, a fácil legibilidade, a ausência de ofuscamento ou quaisquer condiçóes capazes de provocar fadiga visual, apesar dessa habilidade não constar na NR (BRASIL, 1990).

Sinteticamente, na execução musical na OSP observa-se que a carga cognitiva permanece subentendida. Observou-se que habilidades como atenção, memorização, antecipação, capacidade de sincronizar a sua execução com a dos demais músicos, bem como adaptação ao arranjo requerido pelo maestro e ao elevado número de repetiçóes em conjunto são consideradas pré-requisitos para o músico, náo se apresentando prescrição propriamente dita. Tais aspectos são notados em atitudes durante o ensaio, tais como o registro escrito de dicas visuais na partitura, durante os ensaios, além da necessidade de compreensão da informaçáo fornecida verbalmente pelo maestro e das mudanças no arranjo da obra, para a adequaçáo coletiva e/ou requerida.

Foram referidos como inerentes à atividade musical outros itens que apresentaram desvio considerável dos padrōes recomendados na classificação do analista e na confrontação, dentre os quais: posturas de trabalho e movimentos; restrições no trabalho; repetitividade no trabalho; atenção; e ruído. Ressalta-se que, justamente por serem considerados aspectos comuns na prática musical, especialmente a presença da dor causada por tais fatores e o uso de estratégias de gerenciamento, pelos músicos, para não interromperem o exercício profissional, esses podem ser considerados fatores de risco para o adoecimento (COSTA; ABRAHÃO, 2004).

\subsection{Organização do trabalho na OSP}

É possível postular ainda a presença de dores e tensôes associadas a uma sobrecarga proveniente de confrontos entre lógicas distintas na situação de trabalho. Assim, a atuação da organização do trabalho sobre o indivíduo demanda estratégias de regulação frente às normas impostas, cobranças e hierarquia rígida, sendo considerada eixo transversal na análise das situaçôes de trabalho (COSTA; ABRAHÃO, 2004).

Durante os ensaios da OSP foram observadas dificuldades constantes dos músicos para atingirem os resultados esperados pelo maestro durante solicitaçóes, por várias repetiçóes do mesmo trecho, o que notavelmente gera tensão e irritabilidade no grupo. A dinâmica imposta pelo maestro à orquestra, a rotina de ensaios, a programação e a autoridade (COSTA; ABRAHÂO, 2004) assumem papel fundamental na estruturação do fazer musical dos músicos na OSP.

Considera-se que o desenvolvimento desse estudo deu-se em fase de readaptação dos músicos a uma nova gestáo: nova diretoria do Centro Cultural Teatro Guaíra, entidade pública à qual está filiada a OSP, e mudança do maestro ocorrida no mesmo ano. Além disso, contemporaneamente à realização do estudo foram citados publicamente (em matérias veiculadas na mídia, impressa, da internet e da televisão) problemas estruturais na manutenção da OSP, tais como a carência de organização na programação antecipada de concertos e barreiras referentes à contratação por funcionalismo público, que não ocorre há cerca de 20 anos.

Ressalta-se que, em consonância à literatura e à estrutura original dessa orquestra sinfônica, há sobrecarga de trabalho nos ensaios para os músicos de cordas, especificamente os violinistas, os quais tocam durante praticamente todo o período e em todos os ensaios (o que náo ocorre com os outros naipes), pois estáo presentes em maior número e são considerados a base da produçấo sonora.

Segundo Lancman e Jardim (2004), a exigência pela otimização da produtividade reflete-se diretamente na intensificação do ritmo de trabalho, desconsiderando, na maioria das vezes, os aspectos anatômicos, fisiológicos e cognitivos humanos. Ao sobrecarregar seu organismo de forma prolongada, o trabalhador se torna mais vulnerável ao desgaste precoce e a quadros de adoecimento. Assim, é necessária a reflexão sobre a necessidade de acompanhamento efetivo, principalmente para a categoria violinistas.

Quanto à variabilidade de prescrições, foi constatada ainda a imprevisibilidade na tarefa, principalmente no que se refere a cancelamentos e mudanças nas datas e locais dos ensaios (informaçóes repassadas também aos pesquisadores), algumas vezes com exiguidade de tempo. A mudança do repertório 
previsto no cronograma, por no mínimo duas vezes ao mês também foi relatada pelos músicos como fator de pressão temporal, assim como exigências de antecipação e memorização rápidas, que interferem na carga de trabalho e na qualidade da produção.

Por último, outro fator constatado foi o comprometimento da autonomia no conteúdo do trabalho dentro da hierarquia da orquestra. Segundo referido pelos trabalhadores, os músicos não têm participação nos processos de planejamento, preparação ou inspeção de sua produção coletiva, nem na estrutura organizacional como: cronograma (datas, horários, locais); definição de repertório e arranjo; inclusão de solistas, contratação de maestro e/ou outros instrumentistas para concertos específicos; análise da produtividade (interferência no processo da orquestra); e questóes administrativas (compra de equipamentos ou materiais). Assim, apesar de náo se poder considerar o fazer musical como "tarefa simples" ou "operação", os músicos executam apenas uma parte do trabalho, a execução coletiva da obra musical, fator capaz de interferir significativamente na satisfação individual no trabalho.

\subsection{O delineamento da ação em Terapia Ocupacional}

De acordo com Gonçalves et al. (2005), na relação dialética entre a Terapia Ocupacional e a interface saúde-trabalho, utilizando-se da Análise Ergonômica do Trabalho, o terapeuta ocupacional decompóe a atividade de trabalho buscando conhecer o trabalho real, compreendê-lo e então transformá-lo (LANCMAN; GHIRARDI, 2002). Suas propostas visam náo somente o levantamento e análise de riscos para a diminuiçáo da exposiçáo dos trabalhadores e o cumprimento da legislaçáo mas, também, atuar com intervenções educativas e preventivas para a reflexáo dos trabalhadores enquanto protagonistas de suas açóes. O terapeuta ocupacional adquire o papel de facilitador entre os trabalhadores

[...] na construçấo de um processo de reflexão sobre o próprio trabalho, permitindo uma apropriação e emancipação que conduzam a uma reconstruçáo coletiva do trabalho [...] (LANCMAN; GHIRARDI, 2002, p. 48).

Assim, o estudo realizado na OSP indica a possibilidade de atuaçáo do teraputa ocupacional. Complementando essa perspectiva, Gonçalves et al. (2005, p. 88) afirmam que a "[...] identificação dos fatores ergonômicos tem possibilitado uma melhor atuaçáo de toda a equipe profissional que atua nessa área." Segundo as mesmas autoras, a área de saúde e trabalho constitui um desafio para a atuação interdisciplinar e requer esforços em conjunção para uma compreensão efetiva da realidade, na elaboração de propostas que a abordem em sua complexidade.

\section{Considerações finais}

A partir do estudo foi possível considerar que a metodologia possibilitou o reconhecimento da dimensão física, evidenciando desvios em relação à antropometria dos postos de trabalho e à biomecânica ocupacional, os quais levam à adoção de posturas inadequadas em período prolongado, dentre os picos de atividade física de alta exigência no tocar, além da constatação da quantidade e duração insuficientes das pausas previstas. Evidenciou-se ainda limitação importante na Norma Regulamentadora 17 quanto à não especificidade sobre a natureza da maioria das situaçōes de trabalho, excessivamente genéricas, sobre a adequaçáo das condiçóes de trabalho, e implicações negativas na identificação e vigilância das situaçóes potencialmente nocivas à saúde dos trabalhadores. Constatou-se que a verticalização na tomada de decisóes e a rigidez hierárquica no tocante à produtividade, produção e qualidade no trabalho eram determinantes na satisfaçáo dos músicos, o que pode interferir no processo saúde-adoecimento relacionado ao trabalho.

Os aspectos relacionados à higiene ocupacional e segurança do trabalho - ruído, iluminação e ambiente térmico -, no contexto de orquestra, como foram abordados superficialmente, indicam a necessidade de uma investigaçáo mais aprofundada para a prevençáo de riscos à saúde dos músicos, assim como a necessidade de investigação das dimensões cognitiva e psíquica, implicando na necessidade da abordagem holística da situação de trabalho em orquestra sinfônica.

$\mathrm{Na}$ discussão sobre a atuação do terapeuta ocupacional foi possível evidenciar a contribuição singular desse profissional no que se refere à análise da atividade de trabalho, para a identificação e eliminação de fatores de risco à saúde dos trabalhadores, os músicos de orquestra. É emergente a necessidade da apropriação de metodologias como a AET pela Terapia Ocupacional em sua prática no campo Saúde e Trabalho, bem como a investigação de situaçóes de trabalho ainda pouco abordadas, como a do músico de orquestra.

\section{Referências}

AHONEM, M.; LAUNIS, M.; KUORINKA, T. (Eds.). Ergonomic Workplace Analysis (EWA). Tradução de João 
Alberto Camarotto. São Carlos: UFSCar/DEP, 2001. [Original de 1989].

ANDRADE, E. Q.; FONSECA, J. G. M. Artista-atleta: reflexôes sobre a utilização do corpo na performance dos instrumentos de corda. Per Musi, Belo Horizonte, v. 2, p. $118-128,2000$.

BRASIL. Ministério do Trabalho e Emprego. Norma Regulamentadora no 17: ergonomia. Brasília: Ministério do Trabalho e Emprego, 1990. (Normas Regulamentadoras).

CHONG, J. et al. Occupational Health Problems of Musicians. Canadian Family Physician, Mississauga, v. 35, p. 2341-2348, 1989. PMCid:PMC2280293.

COSTA, C. P. Quando tocar dói: Análise Ergonômica do Trabalho de Violistas de Orquestra. 2003. $147 \mathrm{f}$. Dissertação (Mestrado em Psicologia Social, do Trabalho e das Organizaçôes)-Instituto de Psicologia, Universidade de Brasília, Brasília, 2003.

COSTA, C. P.; ABRAHĀO, J. I. Quando o tocar dói: um olhar ergonômico sobre o fazer musical. Per Musi, Belo Horizonte, n. 10, p. 60-79, 2004.

FRAGELLI, T. B. O. Perspectiva social ecológica e promoção de saúde: um estudo entre músicos. 2008. 93 f. Dissertação (Mestrado em Psicologia Social, do Trabalho e das Organizaçóes)-Instituto de Psicologia, Universidade de Brasília, Brasília, 2008.

FRANK, A.; VON MÜHLEN, C. A. Queixas musculoesqueléticas em músicos: prevalência e fatores de risco. Revista Brasileira de Reumatologia, São Paulo, v. 47, n. 3, p. 188-196, maio/jun. 2007.

GONÇALVES, R. M. A. et al. O trabalho dos agentes de trânsito do município de São Paulo: uma análise ergonômica. Revista de Terapia Ocupacional da USP, São Paulo, v. 16, n. 2, p. 82-89, maio/ago. 2005. http://dx.doi. org/10.11606/issn.2238-6149.v16i2p82-89

GONIK. R. Afecçôes neurológicas ocupacionais em músicos. Revista Brasileira de Neurologia, Rio de Janeiro, v. 27, n. 1-4, p. 9-12, 1991.

GUÉRIN, F. et al. Compreender o trabalho para transformá-lo: a prática da ergonomia. São Paulo: Edgard Blücher, 2001.
LANCMAN, S.; GHIRARDI, M. I. G. Pensando novas práticas em terapia ocupacional, saúde e trabalho. Revista de Terapia Ocupacional da USP, Sáo Paulo, v. 13, n. 2, p. 44-50, maio/ago. 2002. http://dx.doi.org/10.11606/ issn.2238-6149.v13i2p 44-50

LANCMAN, S.; JARDIM, T. A. O impacto da organização do trabalho na saúde mental: um estudo em psicodinâmica do trabalho. Revista de Terapia Ocupacional da USP, São Paulo, v. 15, n. 2, p. 82-89, maio/ago. 2004. http://dx.doi.org/10.11606/issn.2238-6149.v15i2p82-89 MOURA, R. C. R.; FONTES, S. V.; FUKUJIMA, M. $\mathrm{M}$. Doenças ocupacionais em músicos: uma abordagem fisioterapêutica. Revista Neurociências, São Paulo, n. 8, v. 3, p. 103-107, 2000.

OSTWALD, P. F. et al. Performing Arts Medicine. West Journal of Medicine, San Francisco, v. 160, n. 1, p. 48-52, jan. 1994. PMid:8128702.

PETRUS, A. M. F.; ECHTERNACHT, E. H. O. Dois violinistas e uma orquestra: diversidade operatória e desgaste músculo-esquelético. Revista Brasileira de Saúde Ocupacional, São Paulo, v. 29, n. 109, p. 31-36, 2004. http://dx.doi.org/10.1590/S0303-76572004000100005 SELIGMANN-SILVA, E. Desgaste mental no trabalho dominado. São Paulo: Cortez, 1994.

TRELHA, C. S. et al. Arte e saúde: frequência de sintomas músculo-esqueléticos em músicos da orquestra sinfônica da Universidade Estadual de Londrina. Semina: Ciências Biológicas e da Saúde, Londrina, v. 25, p. 65-72, jan./dez. 2004. http://dx.doi.org/10.5433/1679-0367.2004v25n1p65

WATANABE, M.; GONÇALVES, R. M. A. Relaçóes conceituais entre terapia ocupacional e ergonomia. In: LANCMAN, S. Saúde, Trabalho e Terapia Ocupacional. São Paulo: Roca, 2004. p. 19-70.

WATANABE, M.; NICOLAU, S. M. A terapia ocupacional na interface da saúde e do trabalho. In: DE CARLO, M. M. R. P.; BARTALOTTI, C. C. Terapia Ocupacional no Brasil: fundamentos e perspectivas. São Paulo: Plexus, 2001. p. 155-171.

ZAZA, C. Playing-related musculoskeletal disorders in musicians: a systematic review of incidence and prevalence. Canadian Medical Association, Ottawa, v. 158, n. 8, p. 1019-1025, 1998. PMCid:PMC1229223.

\section{Contribuição dos Autores}

Jaqueline de Lima: levantamento bibliográfico nos bancos de dados, realização dos procedimentos da pesquisa em campo, concepção e redação do texto. Angela Paula Simonelli: orientação da pesquisa e dos procedimentos, revisão do texto.

\section{Notas}

${ }^{1}$ Pesquisa desenvolvida pelo Departamento de Terapia Ocupacional da Universidade Federal do Paraná (UFPR), conforme as normas éticas estabelecidas, analisado e aprovado pelo Comitê de Ética em Pesquisa em Seres Humanos do Setor de Ciências da Saúde da UFPR, em 25 de agosto de 2010. Artigo elaborado a partir do Trabalho de Conclusão do Curso de Terapia Ocupacional da UFPR, 2011. 